\title{
Developing Student's Motivation to Learn Foreign Language in Tertiary Classroom and Beyond
}

\author{
Natalia V. Aksenova \\ National research Tomsk polytechnic university, Tomsk, Russia \\ Email: polozova15@rambler.ru \\ Denis V. Shepetovsky \\ National research Tomsk polytechnic university, Tomsk, Russia \\ Dsh23@yandex.ru \\ Veronika E. Mironova \\ National research Tomsk polytechnic university, Tomsk, Russia \\ veronicka84@yandex.ru \\ Svetlana N. Stepura \\ National research Tomsk polytechnic university, Tomsk, Russia \\ Lana3670@rambler.ru \\ Inna L. Pichugova \\ National research Tomsk polytechnic university, Tomsk, Russia \\ inpich@mail.ru
}

Doi:10.5901/mjss.2015.v6n5s1p240

\section{Abstract}

Correction of time deficit in acquiring the required level of command of English is possible only due to more active use of extramural activities: student's independent work and project work. Unfortunately, many students, especially those at a lower levels of command of language have insufficient motivation to continue their learning. The aim of the paper is to present a set of techniques used to boost motivation to learn English among students of engineering tertiary school. The techniques used were partially borrowed from secondary and primary school practice and adapted to suit the new demographics. At the heart of the method is the notion to make students use language outside classroom in preselected but non-adapted context: reading excerpts from Wikipedia, declamation, creative tasks. It is further informed by psychology and builds upon feeling of fulfillment binding it with studying English. The method was applied to several group of engineering students and resulted in some increase in attendance and significant increase in attempts at homework which we interpret as indicators of increased motivation. Intensive use of different games, unusual tasks and assignments allowed students to show their creative ability and imagination. The use of authentic materials while a naturally more challenging task is more rewarding not only from linguistic point of view, but motivationally as well. Many students regardless their level of English are interested in technology and results of modern research. This interest may and should be used to boost motivation.

Keywords: extramural activities, motivation, ESL, non-linguistic.

\section{Introduction}

Teaching a foreign language is a complex process in its requirements of adaptation in an alien linguistic environment, in preparation to reproduce foreign speech and in motivation to learn the language.

The processes of international integration in science and industry advance new and more precise requirements to technical specialists' command of foreign language. Teaching of foreign languages in the tertiary school is built around those requirements and the curriculum is changed accordingly. Thus, a new curriculum for English Language in Tomsk 
Polytechnic University calls for the following objective of teaching the foreign languages to form intercultural communicative foreign competence of students at a level sufficient for solving communicative tasks in professional activity and performance of further learning and cognitive development.

The curriculum provides for two classes of 90 minutes each week, totaling at 128 contact hours a year. Every year brings to the university new students of lower and lower level of proficiency, that is why there are more and more groups of Elementary level, approximately matching CEFR level A1. Two years ago for the first time groups were created for students who came with zero knowledge of English after the high school. Every year more and more students strive to get into these groups.

Such dynamics defined by a crisis in school education calls for consideration to adopt in tertiary education methods previously used in secondary school teaching and to use them in teaching elementary English. Undoubtedly, these methods have to be extended with orientation towards professional communication, which is a characteristic of tertiary education but is impossible without basic knowledge. English language is included into the tertiary education system due to the fact that command of English is required to achieve any significant results in science and professional development in almost any sphere of activity nowadays. For example, a standard requirement for applicants for foreign probation is the command of English at CEFR B2 level and leading British universities require C1 level. Requirements of the Tomsk Polytechnic University's Curriculum for English Language are aimed at reaching B1 after a year of studies, which seems unrealistic to many.

There are different estimations of time expenditures necessary to achieve a certain level of command of language. We hold that the generalization of such estimates presented by Tony Gurr, (Gurr, 2014) a Turkish instructor of English, is highly realistic: A1-80-100 contact hours (called Guided Learning Hours in original), A2-180-200, B1-350-400, B2550-600 contact hours. That is, a student at CEFR A1 would need 250-300 contact hours to achieve B1 which is twice or thrice the available time resources.

We may agree with A.E. Burenok (Burenok, 2004), that the time resources allocated for class work in foreign languages in non-linguistic tertiary schools are insufficient and thus an issue arises to create conditions for fruitful extramural and independent activities of students as well as with S.E. Zaytseva (Zaytseva, 2013), who argues that despite all the undeniable advantages and importance of the English language the students in non-linguistic majors mostly do not see it as a necessary subject to study guided by a notion that they will not require it in their future professional activity and by perceived complexity, etc. We may add that the perceived complexity of language apprehension develops largely from the sheer time consumed by it in school to no avail.

Correction of time deficit in acquiring the required level is possible only due to more active use of extramural activities: student's independent work and project work. The curriculum supplies $40 \%$ of total student's time to study language for this type of activities. A new problem arises: that of students' motivation. Unfortunately, many students, especially those at lower levels of command of language have insufficient motivation to continue their learning. Due to different causes they did not get basic knowledge during their school years and now they do not believe in possibility to catch up with their more linguistically advanced peers and ever reach a level allowing for use of foreign language outside of language classroom.

Study of a foreign language is a process with delayed return which has a negative impact on motivation to continue it. In the absence of not only immersion into the linguistic environment but also as much as a direct contact with native speakers (which is very true for Siberia and English language) the students have no direct necessity to study the English language. Low level of command does not allow indirect contact with the linguistic medium through books, movies and TV programs.

Learning of the English language is aimed at receiving advantages and dividends in the future when a certain level of proficiency is obtained, an event happening at different time for different students. Such low predictability of results lowers motivation even more, while independent extramural work requires strong enough motivation which shall be maintained for a prolonged period of time. Short-term mobilization of efforts is unacceptable in this case, because to attain any level of proficiency it is necessary to employ long-term memory. For effective use the linguistic information must be kept in the long-term memory while short-term intensive sessions without supporting and continuous use of studied skills uses the short-term memory which is known to everybody who was a student, learnt a lot of material in the night before the exam and could not remember any of it a week after the successful passing of the examination. Intensive learning of language is possible, but it shall be supported with intensive practice as it happens with emigrants immersed into the language environment. This is close to impossible in the situation of non-linguistic tertiary school.

Composition of foreign speech is impeded not only by lack of knowledge of necessary linguistic units. E.I. Chaplina (Chaplina, 2006) also shows many difficulties induced by psychological barriers. Two of them are the most prominent:

1. Lack of motivation to practice language in the classroom setting. A student in the classroom knows that their 
interlocutor shares with them a common language (in our case Russian) and often the student switches back to native language in case of communicative failure instead of continuing to use the studied language to mend the communication. Paradoxically, practice shows that almost all students have enough command of language to explain the unclear moments or ask for classification and continue conversation.

2. Fear of mistake which is the highest for the lowest levels of proficiency. Even having a command of vocabulary and grammatical structures the students find it psychologically difficult to use the linguistic material outside the context where it was assimilated. Usage outside the strong context is necessary for fluent speech production.

Such barriers can be removed to a certain degree. The curriculum of the first year provides development of General English competences which will then serve as a basis to develop skills and competences in Business English and Professional English. So, at this level we may use cultural studies and cultural awareness as a tool to develop motivation. The students attain knowledge not only of language, but of culture of the countries where the language is spoken as well. Such knowledge is not only necessary for correct organization of communicative acts with the native speakers, but, as practice shows, causes a great deal of interest among students, far greater than typical standard situations (at a doctor's, in the shop, etc) where only linguistic component differs and cultural component stays intact.

The most important component of success in teaching (and learning) a foreign language is development and maintenance of students' motivation at a necessary level. In applications to educational process it is possible to subdivide motivation into internal and external. Both are equally important for studying a foreign language. Internal motivation is caused by the process of education itself. The student is interested in a foreign language, its structure and peculiar characteristics. Communication is the main aspect in this context; the student connects their intellectual development with the mastery of foreign language. Internal motivation depends on such personal qualities of the student as foresight, ambition, prediction of professional success; the future specialist is aware of linguistic competence necessity that will help improve intellectual aspect of personality, work at self-development. The sources of external motivation are the following: the desire of students to please their parents, to pass the exam, to compete with groupmates, to have high results in education, or praise and encouragement of the interlocutor and other aspects of social nature.

Motivation is an important condition of efficient foreign language learning as it has a certain number of functions:

1. Incentive function - motivation stimulates students to fulfill educational cognitive activity to achieve objectives;

2. Developmental function - a student with high motivation is extensively involved in the process of study developing intellectual abilities, thinking, and required skills;

3. Organisational function - motivation and discipline are inseparably connected with each other; if there is motivation then a student plans his foreign language and academic activities, expected results, work stages and periods of tasks performing more thoroughly and efficiently;

4. Psychological function - an essential function of motivation to foreign language study as communication and interaction with people, especially with native speakers, cannot exist without such phenomenon as foreign language. Communication implies psychological contact with people; it takes place only on the basis of motivation to foreign language interaction;

5. Oriented function - help student understand and focus on teaching and linguistic material, foreign language information; it includes the ability to search for necessary data and differentiate major and minor problems.

Taking into account the number of available contact hours and their absolute insufficiency (with the possible exception for some intensive immersion courses) for development of necessary linguistic skills in the given time period without active use of extramural activities, the correct organization of such activities and stimulation of motivation become crucial elements of success.

In this article we want to share successful experience in organization of extramural activities among the students of technical tertiary institution studying the English language. Often we encounter unwillingness on the student's part to set aside enough time to complete classic homework based around reading, translation and selection of correct grammatical structures. Bringing up different causes and excuses they tend to miss the classes due to perceived insufficient importance of the foreign language studies. Students coming from school with low level of proficiency do not lay much hope onto raising their command of language during the limited time allocated for this task in the university. It makes them to decide to spend as little time as possible studying English and to redistribute their time in favor of special subjects. As the English level instructors in a non-linguistic tertiary school we see our task as drawing more attention to systematic attainment of the subject's objectives and disciplined regular studies.

\section{Methodology}

The main problem voiced by the students is lack of motivation to study English due to perceived impracticableness of this 
process as defined by murky prospects of achieving any practical results.

During their work in tertiary education the authors independently developed individual techniques intended to boost motivation. These techniques are largely transformations and adaptations of techniques used to work with primary school pupils and were practiced separately, some of them for several years with good results. However, the results were never objectively tested and notion of their effectiveness was based on subjective assessment of students' interest and their achievements.

Thus, we decided to combine separate techniques previously used by individual instructors into a complex method aimed at raising motivation to study the foreign language and based upon involvement of students into extramural activity in the form of contests, festivals, conferences and project work. This complex method we wanted to subject to objective testing.

Before we started we surveyed 45 first year undergraduate students with the aim to find out what motivates them to study foreign language. The students had to define weights of four different motivations on a scale from 1 to 10 : to fulfill university curriculum, to travel abroad, to work abroad, to read foreign books and watch foreign TV programs and movies and to self-improve. The same students were also asked to estimate their level of English using the same scale. The results show obvious correlation between domination of wish to fulfill the curriculum and self-improve with lower levels of command of language.

Table 1. Self-assessed motivation and level of English

\begin{tabular}{|l|c|c|c|c|}
\hline & \multicolumn{4}{|c|}{ Self-assessed level of English } \\
\hline Motivation to study English & $1-2$ & $3-4$ & $5-6$ & $7-8$ \\
\hline To perform well in the university & 9.0 & 6.5 & 6.2 & 4.8 \\
\hline To travel around the world & 4.4 & 7.4 & 7.6 & 8.0 \\
\hline To work abroad & 5.5 & 5.8 & 6.4 & 7.2 \\
\hline To read books and watch videos in English & 3.2 & 5.0 & 5.4 & 6.2 \\
\hline For self-improvement & 8.0 & 6.5 & 4.2 & 4.1 \\
\hline
\end{tabular}

We interpret this correlation in the following way. On the one hand, after several years of studying English in school with no practical result the students do not believe in possibility to achieve progress in their knowledge and command of language that may allow unsupervised use of language for communication. On the other hand, studies show that a will to get good grades and especially the will for self-improvement are weak motivations and if they dominate in a person they cannot supply interest in a subject of study long enough and at a required level. Only when they have supportive roles they can enhance communicative motivation of other choices (books/movies/TV and direct contact with foreigners). Thus, to raise effectiveness of teaching it is necessary, first of all, to develop the communicative component by demonstrating to students the fact that they can already reach communicative success while it is of a limited nature. Use of preselected but not adapted fragments of authentic texts and video materials as bases for general understanding task and discussions works in this direction. Another element to develop student's assurance in their communicative competence is their involvement in extracurricular and extramural activities.

To raise cultural competence we implemented extracurricular events tied to specific celebrations of the Englishspeaking countries. They resulted in increased cultural awareness and allowed for extension of creative individual and group work. One of the celebrations in question is Halloween, which is alien for our culture. Every year, due to peculiarities of planning it falls on the so-called conference week, when the students take interim assessment, colloquia and cover their academic arrears amassed from the beginning of the term. Despite the lack of practical training classes and lectures, the students are overloaded with tasks and preparations. Practical application of the foreign language during the conference week is to some degree a recreation and to some degree gratification from participation and erudition.

Creative work plays an important role in increasing the level of motivation to foreign language study among the students where various types of activities are included: assignments of complex advanced nature, presentations, project work, participation in academic competitions and conferences, testing for international language certificate (for students with advanced level of foreign language), etc. For example, a great number of students are involved in scientific work a significant part of which is done by them independently.

Special attention is paid to different competitions where students are able to use their imagination and creativity, sing, dance, dramatize or recite the poetry in the foreign language.

Reading tasks based on Wikipedia articles were introduced into the teaching situation to increase motivation as 
well. Students of lower level of command of English used Simple English Wikipedia which is basically in Basic English with some extensions. Students regularly use Wikipedia, thus an ability to read it in another language is a useful practical skill. It raises immediate practicality of English language studies because English version of Wikipedia has more articles and the articles are usually longer than those in the Russian version.

Extracurricular and extramural activities are organized and coordinated through the groups (communities) created in the VKontakte social network (vk.com), which is far more popular in Russia than Facebook and where almost every student has an account. The groups were created as Closed, where only the authorized members can access the information while outsiders can only see a list of members. This allowed not only to limit ubiquitous spam messages but to empower students as well: on the one hand, it is a habitual medium of the social network, on the other hand, the audience is limited thus audience-induced fear of mistake is less of an issue. In those groups (each of the instructors has their own) a selection of information from the university web-site is given that may be of interest to the students of foreign language, such as announcements of conferences and competitions where participation is possible whether in person or by correspondence. Such information constitutes about a quarter of messages on the group's wall (an analogue of Facebook's Timeline). Necessary information about office hours and links to homework materials is made available through this outlet as well. The group also used to organize work with essays, which are submitted through the Discussion instrument and then may be discussed or assessed there. The fact that the submitted work and its assessment will be seen by the peers significantly limits plagiarism and use of machine translation. Another benefit is an ability to learn not only from one's mistakes but from mistakes of peers as well. Links to educational materials may be published in the groups not just by the instructor, but by students sharing their findings during preparation for a creative task. Except for the advantages above comparison with direct mail list gives a disadvantage: students are sometimes late to react to urgent notifications because they got lost in their News timeline.

A common means to organize the extramural activity of students are so called Lab Works, which are test-based and completed by students on the university's Moodle LMS server. Tasks that were developed to match studied lexical and grammatical topics are used mainly as an assessment tool.

Different competitions with linguistic element and oriented towards different levels of language fluency. Usually a competition contains different nominations some of which may require more serious linguistic skills than others where deficit of fluency may be compensated with creative approach. For example, a competition of graphic works with English captions was held in the institute, the nominations ranged from single panel caricatures accessible to students of lower levels of fluency to comic strips with a developed storyline that require more serious linguistic endeavors. Participation in such competitions, however limited their linguistic component is, gives the student a sense of achievement (because the student actually uses foreign language outside classroom); such sense is boosted in case of recognition of one's effort with a prize. Success and attention become associated with use of English thus increasing motivation to continue studies. Such increase is especially vivid in case of students' group work to prepare a performance. Cooperative creativity unites and gives additional importance to the uniting factors, one of them being a necessity to master some linguistic realities however minor they are. All this invariably results in boost to motivation of students involved regardless of their level of linguistic proficiency. Prize in a competition is a prize for the foreign language by association.

Another element we use in our work is educational sites, mainly Duolingo (duolingo.com) to practice the grammar covered. The choice criteria were: free access to full functional, instructions and interface in Russian, listening exercises, the possibility of regulating the entry level (Aksenova \& Shepetovsky, 2014). The effectiveness of this teaching resource has been confirmed by the investigation in which several hundred students studying Spanish took part. On-line training on Duolingo.com is based on translation method. Each lesson includes 27 questions aimed at the introduction of new lexical units in conjunction with the grammatical structures, as well as testing of the words and structures which are already known to the students. The skills are arranged in a dendriform structure, admission to more complex tasks is after the successful completion of simpler levels, and accordingly, the successful mastering and development of simple skills. Students can send and receive private messages, and take part in discussions and debates on mini-forums attached to each test sentence. The Duolingo web-site gives students the ability to track not only their own success, but the success of their groupmates, thus introducing peer pressure by comparison which boosts motivation.

Six student subgroups have been involved into the work with the resource: four subgroups of elementary level and two subgroups of intermediate level, all in all 45 first-year students.

Another gamification technique used in the classroom is the introduction of a material marker of the student to answer. The toy acting as the marker is a source of tactile sensations which are rare in a foreign language classroom. Furthermore, the contact with the toy allows removing anxiety due to the activation of children's associations; they understand that this is only a game and there is no need to worry about a possible wrong answer. The introduction of the material marker simplifies the process because the toy can be given a name (which is to be further used in grammar 
examples illustrated by moving toys), and if desired, come up with a background story. The character coming through all grammatical examples calls empathy due to the fact of previous acquaintance with it. Empathy tends to cause increased attention.

Thus, using the above-mentioned method considered to be simple - the change in the order of priority controlled by the students during the frontal interrogation with the use of toys - solves several tasks at the same time; tasks that arise when learning a foreign language, such as the reduction of the time spent in a stressful situation, contribution to a friendly atmosphere and more productive work. Likewise, this method makes the lesson more interesting and dynamic.

The communicative approach in foreign language teaching involves the use of real knowledge transmission in the learning process. So, the natural development of language skills strategy should be encouraged by joining the real communicative situation. One of the most advanced means of learning a foreign language is the use of the Voice of America website which helps enlarge the vocabulary. In the process memorization becomes actual as well as the connections with previously studied words which are to be used in composing sentences. A more sophisticated version of this task involves the formation of a coherent text of the made up sentences; it is considered to be able to activate the creativity of students. The work with the vocabulary of frequency lists gives quick result in a form of facilitating common understanding.

\section{Results}

The students have been gradually involved in the use of the Duolingo site.

During the first week the majority of the participating students showed good results largely defined by the fact that the system rewards preterm skills pass; the system is used not to study the basic knowledge which is already known to students. The analysis of the students' activity showed that the majority of students gained 10-30 points every day during the week, and the remaining 150-200 points were gathered additionally during the intensive session on Sunday.

At Tomsk Polytechnic University various scientific conferences are held devoted to both technical and humanitarian spheres. One of the most famous is the conference "Communicative aspects of the language and culture" where students participate with their articles and reports; they chose different topics among which were "Peculiarities of Middle English dialects development", "Language of Shakespeare and its place in English literature", "Stylistic devices of formation of Hamlet's psychological image in the work of Shakespeare", "The history of English names formation", "The dark side of London as a part of history and culture".

A question arose: how to assess effectiveness of our activities? Assessment by grades is impossible because the grades largely depend upon previous knowledge. Grade increment would be ideal, but requires development of test battery and its adjustment for students of different levels of proficiency. As the criteria we chose attendance and homework completion (regardless of grade, just the fact of attempt). We compared data for groups of students where the above described techniques were used with that of other groups. The results are given in Table 2.

Table 2. Attendance and Homework Attempted

\begin{tabular}{|l|c|c|}
\hline & Attendance, $\%$ & Homework attempted, \% \\
\hline Experimental groups & 90 & 78 \\
\hline Control groups & 82 & 60 \\
\hline
\end{tabular}

The table shows that the implemented system has a small positive influence on attendance and significantly influences homework attempt.

\section{Discussion}

Use of Duolingo proved partial success: the novelty of the approach gave some fruit but it quickly wore off. For users with high motivation Duolingo gives great educational opportunities. We hold that gamification that lies in the basis of this educational site is a great mean to achieve necessary results and apply linguistic knowledge to practical use. However, it is not fully gamified, for example, there is no character that makes users to feel sympathy for. Doing quite repetitive tasks for points is only interested for a limited time when it is not supported by emotional connection to what happens on the screen and it is here where Duolingo fails.

As for competitions, from students' comments we know that students feel that not only stimulating part of the event is important (prizes, additional credit, etc) but active participation in social life as well (support from the instructors, 
respect and credit from peers). English language instructor plays a role of trustee who refers the students to select a point to invest efforts into achievement.

Thus, motivation is stimulated at the expense of new advanced technologies and internet resources. However, it is of great importance to mention the requirements to the information resources and material offered to the students. First of all, information used for foreign language classes, including extramural and extracurricular activities should be connected with the future profession of the student. In spite of the fact that the mentioned above sources can be applied for junior students, it is more exciting for them to apply material close to their future specialization to realize their professional identity. It is efficient due to the necessity of developing general and professional skills required at the job market today. Thus, students should be ready to meet changing requirements. Another important aspect in choosing the right information resource is a certain level of sophistication. It means that the material there should contain some difficulties for a student that one is able to overcome. It helps study information in detail that is efficient for developing various skills including in the future professional sphere of the student. Next, information resources should be selected in accordance with the abilities and foreign language level of the student. It is connected with the previous factor as the material presented there should not be too easy or too difficult for students and, at the same time, it should be essential and currently important for them. In the process of foreign language teaching enough attention should be paid to the individual approach to the students, their interests, abilities and needs. Even if a student works independently, at home or is involved in extracurricular activity, a foreign language instructor should monitor and control the work of students giving substantial recommendations. Moreover, it is important to take into consideration all the difficulties an individual student might experience. Every student has certain problems in the process of foreign language study, therefore, the language instructor should realize how to solve these problems in terms of certain specific situation. Furthermore, the process of personal development of an individual student ought to be taken into account.

We consider our work with Wikipedia successful and find support to it in talks with our students who compared English and Russian versions of the same articles and found English ones far more informative on too many occasions. It combined fulfillment of work with authentic text with demonstration of its practical value.

\section{Conclusion}

Thus, we may conclude: extramural and extracurricular activity positively influences different active teaching methods and raises motivation to continue learning by boosting self-esteem and showing practical value of limited knowledge already obtained by student.

Three aspects of personal development influencing on the level of motivation and the selection of information resources can be distinguished:

1. The first set of peculiar characteristics of personal development relates to the process of study itself and includes the following points: the level of foreign language skills, natural abilities, cognitive aspects, critical thinking, uptake of content efficiency, the level of general educational competences and learning strategies.

2. The second set of such characteristics is connected with social and psychological aspects of a student: interaction with people, specific nature of temperament, the ability to work in team or independently, openness to criticism, self-analysis, level and type of motivation to foreign language study.

3. The last set of student's personal characteristics covers needs and interests of students that might be reflected in the educational process during the work with various linguistic sources as well.

To improve the level of motivation certain requirements to educational process should be taken into consideration.

1. The use of authentic materials, articles and results of foreign scientist's research to share their experience in a foreign language with Russian students while a naturally more challenging task for a student is more rewarding not only from linguistic point of view, but motivationally as well.

2. Information studied at the class or as a part of homework should be connected with future profession of the students. Despite the fact that a great part of students have no advanced level of foreign language, they are interested in different terms concerning their specialization and results of modern research. Therefore, it would be important to arrange seminars and lectures in student's professional spheres.

3. Intensive use of different games, unusual tasks and assignments allowing students to show their creative ability and imagination. It significantly increases the level of motivation to more detailed work in a foreign language.

4. The learning process planned on the basis of numerous internet resources and up-to-date computer programs is important as well. On the one hand, it makes the work of the language instructor easier. However, it is necessary to select resources thoroughly in accordance with students' level of knowledge and needs. 
5. Intensive involvement of students in scientific activity helps increase motivation and develop more independence in the process of foreign language learning as students frequently prefer those types of work where they do the research or other exciting assignments themselves. It will be one of the most substantial benefits for them in their future career. All things considered, we may come to conclusion that development of students' abilities and motivation is rather difficult work, therefore, the whole process of education, both curricular and extracurricular should be thoroughly planned and improved on the basis of various information resources and technologies.

\section{References}

Aksenova N.V., Shepetovsky D.V. (2014). The duolingo.com usage in teaching English to students of technical institution, Molodoy Uchyonyy, 7, $484-486$.

Burenok E.A. (2004). Project work as a tool of intensification of professional teaching English to students in tourism sphere. - Synopsis of a thesis. [Online] Available: http://www.dissercat.com/content/vneauditornaya-deyatelnost-kak-sredstvo-intensifikatsiiprofessionalnogo-obucheniya-angliisk (April 20, 2015)

Chaplina E.I. (2006). The strategies to overcome psychological barriers in studying foreign language to students [Online] Available: http://www.dissercat.com/content/strategii-preodoleniya-psikhologicheskikh-barerov-u-studentov-pri-izuchenii-inostrannogo-yaz (April 21, 2015)

Common European Framework of Reference for Languages: Learning, Teaching, Assessment (CEFR) (2014) [Online] Available: http://www.coe.int/t/dg4/linguistic/Cadre1_en.asp (May 1, 2015)

Gurr Tony. How long does it take to LEARN English, hocam? - The "10,000 Hour" Upgrade... [Online] Available: //http://allthingslearning. wordpress.com/2014/02/21/how-long-does-it-take-to-learn-english-hocam-the-10000-hour-upgrade/ (April 24, 2015)

Lisitzina T.B., Ibatullova Y.T., Mustafina A.A., Sadykova E.R., Kozhanova M.B, Shaikhlislamov A.K., Minsabirova V.N. (2015). Principles of professionally-motivating training of students majoring in "Tourism" and the rules for their implementation in practice, Mediterranean Journal of Social Sciences, Vol. 2 S3, 15 - 21.

Zaytseva S.E. (2013) Forming of motivation to study English for students of non-language specialities. [Online] Available: http://najournal.ru/2-2013-gumanitarnye-nauki/283-formirovanie-motivacii-izuchenija-inostrannogo-jazyka-u-studentov-nejazykovyhspecialnostej (May 10, 2015) 